\title{
ADOLESCÊNCIA: MUDA PSÍQUICA À PROCURA DE CONTINENTES
}

Nathalie de Kernier e Dominique Cupa

\begin{abstract}
Nathalie de Kernier Doutora em psicologia, psicoterapeuta analítica; mestre de conferências em psicopatologia, no Laboratório de psicopatologia psicanalítica e agravos somáticos e identitários do Centro de Pesquisas Didier Anzieu,

RESUMO: Período de transtornos somatopsíquicos inéditos, a adolescência repõe em questão os marcos identitários e identificatórios. A metáfora de Anzieu - o Eu-pele — parece-nos fecunda para pensar a adolescência em termos de muda: mudar de pele. O investimento dos limites é especialmente solicitado para conter essas transformações. Este artigo propõe uma reflexão acerca dos conteúdos intrapsíquicos, objetais e sociais que favorecem a muda adolescente.
\end{abstract} Universidade de Paris Oeste Nanterre La Défense. Membro do Collège International de l'Adolescence.

Dominique Cupa Professora de psicopatologia da Universidade de Paris Oeste Nanterre La Défense, Laboratório de psicopatologia psicanalítica e agravos somáticos e identitários, Centro de Pesquisas Didier Anzieu.

Psicanalista, membro da Société Psychanalytique de Paris.

Tradução Pedro Henrique Bernardes Rondon

Palavras-chave: Adolescência; continentes; limites; tentativas de suicídio.

ABSTRACT: Adolescence, a psychical molting season in search for containment. During adolescence, physical and psychic reorganizations are very important and new markers of identity and identifications are thrown back into question. Anzieu's metaphor, the "SkinEgo" ("Moi-Peau"), appears to us very useful to think adolescence as a molting: the skin — i.e. the metaphoric Skin-Ego — is changing. This new transformations need to be contained, so the cathexis of the boundaries is requested. The purpose of the present article is to ponder on the containments favoring the molting of the adolescence. These containments are psychic, object and societal.

Keywords: Adolescence, containments, boundaries, suicide attempt. 
A adolescência implica desconstrução do infantil, para permitir que o sujeito se estruture. Num movimento paradoxal de despojamento de si mesmo o sujeito se retoma para se tornar sujeito de sua história dentro de um corpo "recentemente" sexuado, graças ao trabalho da genitalização. Esse tempo psíquico inclui a experiência do limite. Aqui o limite é espacial e identitário, ligado às representações de um si mesmo que se modifica. De fato, a adolescência é uma questão de mudanças: de início, pelas transformações somáticas; depois, por aquelas que dizem respeito à atividade fantasística e, enfim, pelas modificações que intervêm no conjunto da vida psíquica. Também a questão do limite, colocada em termos de identidade, é indissociável da questão da identidade corporal. A identidade seria alienação caso se restringisse a um princípio de permanência, de relação do sujeito com o idêntico. Mas a identidade se define em relação a um conjunto de dados em transformação, que não se estabelecem de uma vez por todas. A identidade se fundamenta em experiências retomadas e aperfeiçoadas ao longo da vida inteira (MARTY \& DE KERNIER, 2010).

Vamos remontar às primeiras experiências do limite para, em seguida, aprofundar as necessidades de continentes na adolescência em diferentes níveis: a representação no nível intrapsíquico; depois, os rituais sociais; e, por fim, o apoio narcísico parental. Os continentes, particularmente solicitados nesses múltiplos níveis durante esse período de intenso remanejamento psíquico, refletem a qualidade da interiorização dos laços objetais. De suas funções como limite, ao mesmo tempo de individuação e de diferenciação — limites que também regulam as trocas com o outro — vai depender a gestão pulsional. Algumas vinhetas clínicas vão ilustrar as importantes dificuldades de separação entre pais e adolescentes em situações patológicas; dito de outro modo, as dificuldades de inscrever-se naquilo que P. Gutton denomina obsolescência, que tem repercussões atuais não apenas nos adolescentes, mas também numa quantidade de jovens adultos cada vez com mais frequência qualificados como adulescentes.

\section{AS PRIMEIRAS EXPERIÊNCIASS DE LIMITES E A CONSTITUIÇÃO DO EU-PELE}

Winnicott (1952a/1969) insiste particularmente na necessidade de continentes de tranquilização, em especial o continente materno, para que o indivíduo possa sentir-se vivo, para prevenir os sentimentos de perseguição, de desintegração e perda de contato entre o psiquismo e o soma. Acerca da criança que foi suficientemente contida por um ambiente protetor e uma figura parental que se adaptou às suas necessidades, Winnicott escreve: “de modo que ele agora está em cima do muro, em vez de ser levado no colo com “devoção”' (1952b/1969, p.196).

A qualidade dos laços objetais vai permitir (ou não) a interiorização viva dos limites, para se tornar um indivíduo inteiro: primeiro, num plano narcísico, 
distinguindo o animado do inanimado, e experienciando sua própria identidade bem delimitada; em seguida, no plano edípico, reconhecendo sem frustração demais, e com suficiente benevolência, os limites que impõem escolhas identificatórias, e os limites da realidade externa às suas aspirações. Mesmo sendo o alvo da pulsão (FREUD, 1915/1968), o objeto está essencialmente na origem da pulsão (LAPLANCHE, 1999). Esse paradoxo mostra a que ponto a pulsão necessita de um continente para emergir, e para se tornar sempre mais psíquica.

Anzieu (1985) ilustra muito bem essa realidade psíquica através de sua metáfora do Eu-Pele: uma figuração da qual o eu se serve no curso de seu desenvolvimento para representar a si mesmo como um eu contendo os conteúdos psíquicos a partir de sua experiência de superfície do corpo. Essa metáfora é muito rica, uma vez que inclui as funções de manutenção, de constância, de paraexcitação, de significação, de inscrição dos traços sensoriais, de correspondência, de intersensorialidade, de individuação, de apoio da excitação sexual, de recarga libidinal do funcionamento psíquico e de continência. Vamos nos deter em especial nesta última função: o Eu-Pele como continente psíquico.

O ambiente materno, em interação com o Eu-Pele do bebê que está em vias de constituir-se, permite que seja carregada a energia pulsional. Anzieu chama a atenção de que em latim a palavra pellis tem dois sentidos: "a pele", e "tu impeles". Impulso e pele estão ligados desde a origem (CUPA, 2007). Os laços entre continente ou Eu-Pele e impulso pulsional já aparecem em Freud (1923/1981), em Le moi et le ça: ele vê o eu como uma superfície, ou como aquilo que corresponde à projeção de uma superfície. Green acrescenta "uma superfície destinada a receber as representações de objetos e os afetos" (1979, p.49). Assim, "as representações do eu são de fato representações de objeto travestidas como representações do eu por investimento narcísico” (GREEN, 1979, p.52). A partir daí o impulso pulsional se apoiaria sobre essa experiência do limite ilustrada pelo Eu-Pele: um limite suficientemente continente e permitindo, ao mesmo tempo, a troca com o outro. O ser humano, ao longo de toda sua vida, tem a ver com o seguinte paradoxo: para ser si mesmo, é preciso alimentar-se dos outros. Acrescentamos que experienciar a si mesmo passa por pôr à prova os limites, estes proporcionando continentes indispensáveis identitários e identificatórios, em dupla vertente narcísica e edipiana. Os tormentos adolescentes revisam essas referências e invocam então continentes em particular, receptáculos dos conflitos que favoreçam sua representação, sua reelaboração e seu recalcamento.

A adolescência em sofrimento implica, de fato, grande dificuldade para se apoiar numa experiência suficientemente boa do limite, seja pela falta de integração das primeiras experiências ao longo da primeira infância, seja pela falta de referências objetais e de apoios identificatórios estruturantes por ocasião da passagem adolescente, seja pela ruptura maciça dos limites. De fato, o traumatis- 
mo implica ruptura dos limites. Quando é próxima demais ou ausente demais, a relação objetal se torna violenta. Nesse caso, a experiência do limite não se faz de maneira suficientemente estruturante, o Eu-Pele corre então o risco de se tornar poroso demais ou hermético demais, de tal maneira a troca com o outro é vivida como traumática. O objeto se torna "único”, e leva a um estado de "servidão ao outro" (CARDOSO, 1997, p.180). O sujeito se vê invadido pelo objeto e também teme perdê-lo. Nesse caso de aspecto patológico, “a angústia de separação, mais do que ameaça de perda, é uma ameaça da impossibilidade de perder" (idem, p.182).

Todo processo adolescente implica, em certa medida, um trauma, ligado inicialmente ao ressurgimento da problemática da perda (GAMMIL, 2006), e em seguida à revivescência edipiana própria do pubertário (GUTTON, 1991/2003), perda e Édipo estando estreitamente intrincados. Por isso, a necessidade de continentes se faz sentir em especial nesse período de crise e de muda psíquica. Por ocasião de situações patológicas, a expressão dessa necessidade à maioria das vezes está ausente ou, ao contrário, é muito ruidosa.

\section{A NECESSIDADE DE CONTINENTES DURANTE A ADOLESCÊNCIA: MUDA, DESPOSSESSÃO E REPOSSESSÃ $0^{1}$}

A violência pubertária (GUTTON, 1991/2003) provoca reviravoltas inéditas análogas a uma muda, para retomar a metáfora do Eu-Pele. Esses profundos remanejamentos estão ligados à revivescência edipiana no momento da entrada na adolescência — dito de outro modo, "uma brusca entrada (à força) da paixão adulta na ternura da criança: loucura sexual sobre terra virgem” (GUTTON, 1991/2003, p.30) quando a criança quase adolescente se descobre atraída pelo genitor incestuoso. Esses remanejamentos profundos podem se revelar tão perturbadores, talvez mesmo traumáticos, que o adolescente se sente despossuído de seu corpo. A muda psíquica provoca desde então uma “dépeaussession" (CUPA, 2002), efração dos envoltórios psíquicos e dos limites de si mesmo, das diferenças eu-outro, das diferenças de sexo e das diferenças de geração. Patologias ou manifestações comportamentais violentas como a tentativa de suicídio podem revelar a insuficiência de continentes suscetíveis de ajudar o adolescente a se "repeausseder" (CUPA, 2002), a se reapropriar de seu corpo, de sua identidade e de sua história. O recurso ao ato assinala o traumatismo em carne viva e a carência de simbolização. Proporcionar continentes a essa pele perfurada constitui um tratamento psicoterapêutico de primeira intenção, a fim de dar forma e sentido à

\footnotetext{
${ }^{1}$ No original, dépeaussession e repeaussession, neologismos, fazendo trocadilho intraduzível com peau [pele]. (N. do T.)
} 
arrebentação da onda pulsional própria à revivescência edipiana e à sexualidade instintiva concomitante.

A partir da experiência clínica de uma de nós junto a adolescentes em risco de suicídio, o investimento dos limites evolui consideravelmente à distância de uma tentativa de suicídio quando o adolescente aceita uma internação hospitalar terapêutica. De fato, a comparação de dois testes de Rorschach, um aplicado logo após a tentativa de suicídio e o outro um ano mais tarde, analisados de acordo com o método psicanalítico da Escola de Paris (CHABERT, 1998), mostra elevações importantes do índice "barreira" de Ficher e Cleveland (1958) e diminuições significativas do índice "penetração” (DE KERNIER, MARTY \& DEVOUCHE, 2012). A elevação do índice "barreira” traduz uma imagem de si mesmo mais bem integrada, dando conta de um eu cujos limites mais continentes e protetores se restabelecem à distância da tentativa de suicídio.

O Eu-Pele pode desde então ser tecido ou retecido à distância da tentativa de suicídio, proporcionando não apenas uma delimitação de si mesmo em seguida a um vivido de "dépeaussession" [despossessão], compensando os agravos narcísicos, mas também um meio de troca mais confiante com o outro. Os adolescentes que cometem tentativas de suicídio parecem recorrer a um violento ataque a si mesmos, uma “autodespossessão”, em suma, para que a indispensável muda psíquica adolescente possa se exercer. É desejável que uma internação terapêutica suficientemente continente leve o adolescente a transformar seu recurso ao agir numa atividade representativa: em vez de passar pelo ato assassino, pensar o assassinato de si como mudança identitária e identificatória (DE KERNIER, 2012). Dito de outro modo, em vez de matar a fantasia pelo ato, fantasiar o ato assassino para realizar um assassinato simbólico, sendo este inerente à condição humana (MARTY \& CHAGNON, 2006). O assassinato simbólico pelas representações de assassinato durante a adolescência dá lugar a uma muda psíquica. “Despossuir”-se da epiderme infantil, despojar-se dos estigmas do trauma para fazer pele nova, o ato suicida poderia tentar ilusoriamente realizar essa muda convocada a se exercer psiquicamente.

A possibilidade de recorrer à atividade representativa constitui o continente mais fundamental que permite que o adolescente trate a violência pubertária e a simbolize para transformá-la em energia criativa.

\section{A REPRESENTAÇÃO COMO CONTINENTE FUNDAMENTAL}

A partir dos trabalhos de Winnicott, R. Roussillon (1991/2005) desenvolve o paradoxo da representação. A representação nasce de uma formatação por intermédio do meio maleável, definido por M. Milner como "substância intermediária através da qual as impressões são transferidas aos sentidos” (1977, p.862, apud 
ROUSSILLON, 1991, p.133). Esse meio maleável é essencialmente dotado de cinco características: indestrutibilidade, extrema sensibilidade, transformação indefinida, disponibilidade incondicional e animação própria (ROUSSILLON, 1991/2005, p.137). A partir da ambiguidade do conceito freudiano de "representação de coisa”, destacado por J. Laplanche, uma vez que pode designar também a representação inconsciente da coisa e a representação tratada como a coisa, $R$. Roussillon formula a hipótese seguinte: 0 meio maleável está na origem das representações de objeto que representam a própria representação (ROUSSILLON, 1991/2005, p.138). E se o meio maleável representa a atividade representativa, os traumatismos específicos desta têm relação estreita com os déficits de figuras do meio maleável (ibidem).

A situação do meio maleável é difícil de delimitar, aí está seu paradoxo: nem representação - uma vez que é objeto concreto - nem fora da representação - uma vez que representa esta.

A indestrutibilidade do meio maleável permite-lhe apresentar relativa indiferença à quantidade ou a suas variações, ou antes, transforma estas em formas. Transforma as variações de quantidade em qualidade, o que leva ao limite o ponto de vista econômico. Disponível incondicionalmente, numa primeira análise ele não parece inscrever-se facilmente no campo da dinâmica do conflito. (ROUSSILLON, 1991/2005, p.140)

O paraexcitação pode ser comparado ao meio maleável: R. Roussillon lembra que o paraexcitação se constitui pelo sacrifício de uma parte periférica do aparelho psíquico ameaçado de morte, a fim de proteger o todo, a fim de manter vivo o centro do aparelho psíquico (FREUD, 1920/1981). Esse sacrifício inaugural de uma parte do aparelho psíquico permite à totalidade deste proteger-se do retorno de tal efração traumática. "Assim, a vesícula é destruída e sobrevive como o meio maleável — ela pode dessa maneira transformar as quantidades em índice de qualidade - aqui ainda como o meio maleável” (ROUSSILLON, 1991/2005, p.142). O caráter continente parece, portanto, ligado à possibilidade de transformar a quantidade em qualidade e à possibilidade de experienciar a sobrevivência à destruição: uma forma pode ser destruída, mas a maleabilidade subsiste.

Um objeto continente é aquele disponível para acolher uma excitação e dar-lhe forma. Repeitar a forma produzida, tal é a função do continente. A possibilidade dessa formatação implica um conflito: conservar a forma produzida - prenderse a uma representação-coisa — ou conservar a maleabilidade — conservar o processo de representação. “É no a posteriori do jogo de destruição/remoldagem (reconstrução), numa retroação que se descobre a essência do processo de representação e que o meio maleável pode se tornar o representante da função 
representativa, o representante da representação” (idem, p.143). É preciso aceitar destruir a forma para que esta possa ser apreendida como representante da coisa e não como a própria coisa.

A função continente da representação permite manter o pensamento como uma "motricidade interiorizada", para prolongar a célebre fórmula freudiana que encerra Totem e tabu: "No início, era o ato." Transformar a excitação em pensamento, de preferência a eliminá-lo em fuga motora, exige uma possibilidade de "apreender" a experiência, outra maneira de dizer "garantir seu domínio" (idem, p.145). “A experiência pulsional que faz a efração não pode começar a ser ‘boa de representar' senão a partir do momento em que o sujeito pode garantir um primeiro domínio sobre ela, isto é, que tenha sido capaz de contê-la e localizá-la. Ela não pode se tornar uma experiência do eu — portanto, não pode ser representada - a não ser que tenha podido previamente ser subjetivada pelo domínio" (ibidem). O que pode ser representado poderá ser recalcado. As partes da vida psíquica que não são representadas não podem ser recalcadas, embora possam ser “inconscientes”, isto é, não integradas à subjetividade.

A função continente da representação é necessária para a atividade de simbolização, de apropriação subjetiva e subjetivante. O trabalho de simbolização constitui um trabalho de construção que articula o dentro e o fora, o sujeito e o objeto. Envolve também um necessário trabalho de luto do objeto primário, isto é, a renúncia a encontrá-lo no idêntico. Trata-se de um processo paradoxal: "para simbolizar, é preciso e basta fazer o luto da coisa; para fazer o luto da coisa é preciso representá-la e simbolizá-la” (ROUSSILLON, 1999/2008, p.223). Eis aí as duas “duplas obrigações” da simbolização (idem, p.237): em primeiro lugar, representar, simbolizar, é tornar-se presente para o mundo e para si mesmo, apresentar-se ao mundo e a si mesmo para aí investir-se, apropriar-se dele; mas, por outro lado, representar é também tornar o mundo, a alteridade, presente em si mesmo. "Essa dupla obrigação implica a construção, no interior do sujeito, de um espaço para o outro, o não si mesmo, que passa pela representação em si de um espaço de apagamento de si paradoxalmente essencial para definir a identidade como não semelhante a si própria” (idem, p.238). Em segundo lugar, "simbolizar, é trans-formar, dar forma e criar nessa formatação: simbolizar é criar a si e o mundo "para um sujeito”, mas, por outro lado, simbolizar é também "recopiar, identificar, recapitular”. Essa dupla obrigação abre toda a questão do encontrado/criado paradoxal: "de que maneira a repetição-cópia cria a diferença, o novo que, recopiando se produz? (ROUSSILLON, 1999/2008).

O contexto social pode mais ou menos favorecer a capacidade de recorrer à representação e de desenvolver seus recursos internos. A pele psíquica é igualmente contida por uma pele social, forjada por rituais que dão ritmo às passagens. 


\section{OS RITUAIS, CONTINENTES SOCIAIS}

Os rituais podem ser considerados como importantes continentes sociais que tendem hoje a desaparecer. De fato, a passagem adolescente é cada vez menos celebrada nas regras da arte; as sociedades em que existem rituais de iniciação são pouco numerosas e, como M. R. Moro destaca: “Nossa própria sociedade não consegue pensar essa passagem de maneira criativa, com muita frequência pensa-a em termos negativos e excludentes” (MORO, 2004, p.141). A carência de ritos de passagem que pode ser observada em nossa sociedade se acompanha de continuidade cada vez mais confusa entre infância, adolescência e idade adulta, suscetível de turvar as referências identificatórias. "Cada vez é menos conflituoso encontrar seu objeto sexual, marcar-se num ou no outro sexo, talvez mesmo recusar a escolha instalando-se na ambiguidade sexual; em compensação, o conflito se deslocou para a diferenciação das gerações" (OLINDO-WEBER, 2001, p.65).

A repressão excessiva dos comportamentos de risco e o enfraquecimento dos rituais, acompanhado pela evitação de tudo o que pode ser violência, se acompanham de novos transbordamentos e riscos perigosos na adolescência. Ora, os adolescentes têm necessidade de pôr à prova seus limites. Uma sociedade que aumenta desmedidamente uma política de gestão de riscos — expressão paradoxal — não leva em conta as necessidades dos adolescentes, a começar por aquela de ser reconhecido pelo grupo dos adultos, e de que um acontecimento marque solenemente essa etapa. Na falta de seguir os caminhos marcados, eles experienciam a necessidade de imprimir, muitas vezes de maneira arriscada, seu próprio caminho. "Privados de referências e de apoios, de símbolos e de trocas, determinados adolescentes estão na obrigação de procurar sempre mais longe seus limites e os dos que os cercam, mesmo reivindicando morrer para existir" (POMMEREAU, 2001, p.95).

\section{O APOIO NARCÍSICO PARENTAL}

Os continentes familiais participam de maneira preponderante do desenvolvimento do adolescente. A autonomização do adolescente e o necessário distanciamento em relação às figuras parentais são muitas vezes evocados, com toda a razão. Em contraste, o adolescente ainda precisa de tutores para construir sua identidade - e ele manifesta isso também com frequência. Algumas vezes esse enquadramento ainda necessário do adolescente é subestimado. P. Gutton fala de apoio narcísico parental, permitindo o que ele chama de obsolescência. Parafraseando Winnicott, um adolescente sozinho, isso não existe. Já vimos isso: a aptidão a representar garante uma função continente, indispensável à simbolização. Olhando para trás, a função continente da representação se refere à função da mãe, ou 
do casal parental e, mais além, à função de "rêverie materna" (ROUSSILLON, 1999/2008, p.172).

A partir dessa matriz as condições de simbolização se relacionam, por um lado, à função de paraexcitação ou paraquantidade do ambiente, por outro lado, à qualificação, pelo objeto materno, de seu desejo por um terceiro, permitindo que o sujeito saia da especularidade pré-simbólica e antissimbolizante. Na adolescência essas duas condições impostas ao trabalho de simbolização e ao trabalho de apropriação subjetiva têm a ver com aquilo que P. Gutton denomina, por um lado, apoio narcísico parental, por outro, obsolescência. A utilização dos objetos parentais como continentes pressupõe, como por ocasião da primeira infância, uma resposta à destrutividade do sujeito. É isso que R. Roussillon denomina experiência do destruído/encontrado.

O adolescente tem que desinvestir eroticamente seus pais para inaugurar um processo de separação. Este pressupõe uma transformação de sua presença física em apoio narcísico. O fascínio pelo objeto parental vai se apagando pouco a pouco e dá lugar a uma identificação como "continente narcísico". "O caminho a seguir é calçado, garantido, cultivado de maneira permanente pelo operário parental. A qualidade da evolução depende desse trabalho de fundação" (GUTTON, 1991/2003, p.161). Pelo contrário, o "genitor excitante” que se ocupa de seu filho adolescente para encontrar aí alguma satisfação pulsional sem adotar uma função simbolizante, é deletério. Como identificar-se às imagens parentais se estas não ajudam a integrar a diferença das gerações, uma vez que não a reconhecem?

Esta pergunta, formulada por A. Birraux (2004, p.144) está no cerne da problemática do adolescente que tenta o suicídio porque não suporta mais a conflitualidade interna que se impõe com as imagos parentais, já que sua função narcísica está enfraquecida. A morte pode ser invocada como solução para essas tensões internas que o adolescente não consegue aliviar e o ato de suicídio exprime o desejo de que "isso acabe". O ataque ao corpo, objeto externo que substitui o objeto narcísico enfraquecido, exprime uma "necessidade de se sentir existir na tensão, de apagar esta tensão e recomeçar” (BIRRAUX, 2004, p.172).

Suzanne, de 15 anos, pouco após sua tentativa de suicídio, afirmou: 'Nunca aceitei ter minhas regras, porque detesto isso, acho chato. Não gosto porque sinto... sinto... sinto muita, muita dor na barriga quando fico menstruada. Enfim, não gosto, não gosto disso, acho isso um tormento. Além do mais, não tenho vontade de ter filhos.' A razão que atribui a essa recusa a ter filhos mais tarde é o temor de criá-los como seus pais a criam. Ainda mais que ela se vê como seu pai, isto é, 'perturbada', 'cínica', e 'não muito boa nos estudos'. Sua tentativa de suicídio seguiu-se a uma discussão com sua mãe a quem ela, no entanto, fazia muitas confidências. As coisas que sua 
mãe lhe disse deixaram-na muito ferida: 'ela me disse que eu não ia arranjar nada na vida, que eu era nula, que tinha vergonha de que eu fosse sua filha'. Muito sensível ao que sua mãe pensa dela, essa desqualificação de seu ser e de seu futuro foi traumática. Suzanne sente falta especialmente do continente narcísico parental para aceitar as mudanças que se operam nela, para ultrapassar o pubertário e inscrever-se como elo numa corrente intergeracional. Essa situação revela o caráter patogênico de uma insuficiência de apoio narcísico parental. ${ }^{2}$

\section{EM SEGUIDA AO APOIO NARCÍSICO PARENTAL SUFICIENTE, A OBSOLESCÊNCIA COMO CAMINHO PARA A DIFERENCIAÇÃO}

O corpo púbere pode refletir como um espelho as posições edipianas parentais. Os pais têm, também eles, que se distanciar de seu filho que está se tornando adolescente - esse novo outro, ou esse novo par diante do casal parental - e que reconhecer as transformações que se operam nele. "Laios e Jocasta, com sua loucura sedutora e perseguidora, o corpo púbere da inocente e excitante vítima, estão indissoluvelmente ligados”, lembra Gutton (1991/2003, p.82). É preciso tempo para chegar a “certa ‘desparentificação', um achatamento intergeracional, a partir da percepção dessa criança que não é mais criança” (idem, p.85). A evolução psíquica favorável do genitor compreende o reconhecimento do pubertário do filho, o deslocamento da excitação para o parceiro que integra o tabu do incesto no plano interno e grupal, e uma possibilidade de apoiar o eu do adolescente pelas posições de ternura cujo segredo o genitor sexualmente satisfeito possui. "O objetivo é a separação das gerações numa mesma família: cada qual tem que ter seu "ninho de amor"' (idem, p.88). Isso implica uma representação do adolescente por seus pais inscrevendo-se numa organização triangular na qual é reconhecido como portador de um sexo masculino ou feminino capaz de procriar.

Uma inscrição da representação do adolescente num contexto dual não é nada favorável:

O investimento de que o adolescente é objeto encobre seu erotismo, e o mantém como sintoma dos pais. O ressurgimento das posições sedutoras parentais se exerce sob a forma de novas exigências narcísicas repetindo as pulsões que agitam esses mesmos pais em direção a seu 'filho-ainda criança'. (GUTTON, 1991/2003, p.88)

\footnotetext{
${ }^{2}$ Esta ilustração clínica figurava em um artigo de uma de nós, publicado na revista profissional francesa da Educação Nacional Envie d'École. O redator-chefe dessa revista autorizou-nos a publicá-la aqui.
} 
Essa posição entrava a indispensável obsolescência dos pais, isto é, a capacidade deles de deixar-se transformar em objetos inadequados, em "sedutores abandonados". Gutton formula que "a entrada do filho na genitalidade deveria implicar, de maneira mítica, a saída do genitor, sua morte genital” (idem, p.93).

O termo obsolescência sugere que "a entrada do jovem caminha paralelamente à retirada do velho” (idem, p.94). “Seria declarada 'obsoleta' a utilização do objeto parental em benefício de novos objetos” (idem, p.140). Os pais desinvestem a presença física, a carne de seu filho. A limitação ou restrição da identidade de substância entre pais e filhos é uma condição para que a identidade própria do adolescente possa se afirmar, e para que ele possa viver sua própria obsolescência, isto é, desinvestir seus pais. "A obsolescência do adolescente não acontece sem a obsolescência dos pais” (ibidem). Esse processo de obsolescência recíproca permite um trabalho de desconvicção representativa das cenas incestuosas.

Laurence, de 17 anos, que atendemos em seguida à ingestão maciça de soníferos que pertenciam a seu pai, está sofrendo com a separação de seu namorado. Ao mesmo tempo, ela não suporta a atitude superprotetora de seu pai: 'ele tem um pouco de dificuldade de compreender certas coisas, que eu não sou mais a sua filhinha, que... que eu já cresci'. Ele exige em especial que a filha chegue em casa às sete horas da noite. 'Ele tem medo de que me aconteça alguma coisa', deduz, e acrescenta: 'Sei muito bem que é para me proteger, não é para me prejudicar. No fundo, não é para me chatear, é para me proteger, sei muito bem disso, mas às vezes não consigo compreendê-lo’. Mesmo sofrendo com o controle de seu pai em cima dela e com o ciúme dele, ela se dá conta de que seus colegas todos ficaram com ciúme e que esse traço de caráter lhe agradava porque isso provava, sempre, que eles se importavam com ela. 'Cada vez que estou com gente malvada, enfim, malvados entre parênteses, eu me prendo a eles. Aos que são legais eu não me prendo, eu sou esquisita', diz. Seguindo suas associações, ela se lembra de ter tido medo várias vezes, quando era criança, de perder seus pais: 'Às vezes eu sonhava que ou minha mãe ou meu pai morria, [...] Eu ficava com medo de que eles morressem, que lhes acontecesse alguma coisa, ou que alguém os matasse'. Hoje, esse tipo de pesadelo reapareceu: 'Numa casa com meus pais, há alguém que vai querer nos matar, a gente se esconde em toda parte, enfim, eu já sonhei um troço assim, acordei sobressaltada no meio da noite'. Uma lembrança da infância lhe ocorre, e Laurence o reconstrói assim: 'Eu me lembro uma vez, meus pais estavam dando uma festa, eu era pequena, porque estava ainda num troço, num alto, uma espécie de berço. [...] E havia uma mosca e ela vinha, me chateava, fazia bzzz e eu não aguentava mais e começava a chorar. Eu chorava e nunca havia ninguém que viesse me ver. Eu sempre vou me lembrar disso'. A superproteção parental atual subtende uma angústia de perda, ao mesmo tempo de abandono e de intrusão, ancorada na relação entre Laurence e seus pais 
desde a primeira infância. A intensidade dessa angústia entrava o processo de obsolescência no momento das tentativas de deslocamento dos investimentos objetais. Laurence sente seus pais próximos demais ou distantes demais, e não consegue se soltar daí. As relações entre eles, ainda muito infantilizadas, não são reconhecidas como obsoletas. Suas associações a levam a tomar consciência de que esse problema de distância do objeto se repete em suas relações amorosas. ${ }^{3}$

\section{MUDA ADOLESCENTE PORTADORA DE UMA DIFERENCIAÇÃO DE GERAÇÕES}

Esses referenciais teóricos e esses exemplos clínicos mostram a que ponto a presença do adulto ainda é necessária para o adolescente, embora sua trajetória seja paradoxal: apoiar-se sobre peles continentes em níveis múltiplos para mudar, permanecer ligado a seus referenciais identitários e identificatórios para mudar. O apoio narcísico parental abre o acesso não apenas a uma diferenciação possível nas relações do adolescente com seus pais, mas também a uma identificação com a função parental; dito de outro modo, a essa capacidade que o adolescente adquire para se projetar como genitor potencial, no sentido de tornar-se responsável por seus atos e seus pensamentos. Desde então, o adolescente entra na perspectiva das gerações: Ele se distingue ativamente da geração de seus pais e se projeta num futuro no qual pode viver a si mesmo como um genitor potencial. "Fazer geração” (MARTY, 2003) é não somente distinguir-se da geração de seus pais, não ser como eles, não pertencer ao mundo deles, identificar-se com a geração de seus pares, mas também viver a si mesmo como tendo-se tornado, ele próprio, alguém que pode estar na origem da vida, em continuação a seus próprios pais.

Fazer geração é fazer viver em si projetos, é imaginar criar acontecimentos, objetos culturais, é se sentir à altura de dar a vida a um outro que não a si mesmo. A diferença das gerações não é apenas reconhecida, é ativamente reivindicada como um dos elementos que fazem parte da construção identitária do adolescente. Fazer geração é ir além do parental, vivido na infância como referência de origem, de sua própria origem. Não se pode ser genitor senão uma vez que se assuma o fato de ser filho, de ter recebido a vida de outro, e não de si mesmo (MARTY \& DE KERNIER, 2010).

\section{QUAL SERÁ A MUDA PARA OS "ADULESCENTES"?}

"Adulescente" é uma contração das palavras adulto ("adu”) e adolescente ("lescente”). Exprime, "por um lado, adultos que se identificam aos adolescentes para viver;

\footnotetext{
${ }^{3}$ Ver nota 2. (N. do T.)
} 
por outro, jovens que não chegam a renunciar às hesitações de adolescente para ter acesso a uma outra idade da vida” (ANATRELLA, 2003, p.38). Nosso contexto social, empobrecido de continentes psíquicos, pareceria favorecer essa "adulescência”. A organização da personalidade desses jovens adultos ainda está inacabada. Entrando na adolescência cada vez mais cedo, e ante uma esperança de vida cada vez mais recuada, eles desejam retardar ao máximo possível suas escolhas e seus compromissos. Sua precocidade não é fonte de maturidade, uma vez que as tarefas psíquicas da latência da infância estão escamoteadas a maioria das vezes.

Uma quantidade de jovens adultos se queixa frequentemente de falta de apoio, em especial aqueles que, após longos estudos, entram nas empresas com seus diplomas e devem exercer responsabilidades que não estão prontos para assumir (ANATRELLA, 2003). Estados depressivos, muitas vezes mascarados por estratégias de luta antidepressiva, subtendem um sentimento de impotência que se traduz pelo temor de não poder ter acesso às realidades impostas pelo ambiente e, por isso, pelo temor da autoagressão ou da agressão às figuras parentais estendidas ao mundo dos adultos.

Quanto menos seja estimulado o desenvolvimento da atividade representativa, especialmente pela possibilidade de se entregar às suas fantasias, a seus devaneios, e a amar uma solidão num face a face construtivo consigo mesmo, tanto mais o recurso ao ato corre o risco de entrar em cena, e tanto mais o sujeito estará prisioneiro do temor de que suas fantasias se confundam com seus atos. Compreende-se então como as fantasias inerentes à condição humana, e mesmo indispensáveis para todo desenvolvimento psíquico, tal como a fantasia de assassinato, facilmente vão escorregar em direção ao ato (DE KERNIER, 2008; DE KERNIER, CANOUÏ \& THOUVENIN, 2010).

O trabalho psicoterapêutico desde então tem por alvo desenvolver os recursos psíquicos para que os roteiros assassinos possam ser contidos pelo pensamento, e lhes seja dado um sentido (DE KERNIER, CANOUÏ \& GOLSE, 2010). A muda psíquica só é possível pela aceitação de uma “dépeaussession" ["desapropriação”] psíquica necessária, implicando que se leve em conta objetos totais e escolhas identificatórias. Escolher implica de fato a renúncia, e para poder renunciar é preciso ter sido suficientemente rico de representações de desejos prévios, e ter elaborado bastante a problemática da perda reativada durante a adolescência. Os adolescentes têm necessidade de se apoiar sobre objetos parentais que não sejam nem próximos demais, nem distantes demais, para renunciar aos objetos parciais infantis e reconquistar os objetos totais e diferenciados.

Conter a muda psíquica adolescente por meio de uma presença adulta que esteja a uma distância adequada favorece a travessia da passagem adolescente.

Recebido em 22/4/2012. Aprovado em 12/6/2012. 


\section{REFERÊNCIAS}

ANATRELLA, T. (2003) “Les adulescents”. Etudes, 399 (7), p.37-47.

ANZIEU, D. (1985/1995) Le Moi-peau. Paris: Dunod.

BIRRAUX, A. (2004) Le corps adolescent. Paris: Bayard.

CARDOSO, M. Rezende (2007) "Les états limites: la question du pouvoir de l'autre”, in MARTY, F. \& coll. Transformer la violence? Traumatisme et symbolisation. Paris: In Press, p.177-194.

CHABERT, C. (1998) Psychanalyse et méthodes projectives. Paris: Dunod, Les Topos.

CUPA, D. (2002) La pulsion de cruauté. Revue Française de Psychanalyse, 66 (4), p.1073-1089.

. (2007) Tendresse au négatif. Le Carnet PSY, 118 (5), p.27-33.

DE KERNIER, N. (2008) Quête d'intimité à l'adolescence et imagos parentales intrusives, Dialogue, 182, p.89-103.

(2011) Le soutien narcissique parental, un contenant nécessaire durant l'adolescence. Envie d'Ecole (revue de la Fédération des Rééducateurs de l'Education Nationale), 68, p.13-15.

. (2012) Suicide attempt during adolescence: a way of killing the infans and a quest for individuation-separation. Crisis: Journal of Crisis Intervention and Suicide Prevention, 33(5), p.290-300.

CANOUİ, P. \& GOLSE, B. (2010) Prise en charge des adolescents hospitalisés à la suite d'un geste suicidaire ou d'une menace suicidaire, Archives de pédiatrie, 17(4), p.435-441.

\& THOUVENIN, B. (2010) Geste suicidaire, expression agie d'une violence familiale tacite ?, L'Evolution Psychiatrique, 75(1), p.123-137.

MARTY, F. \& DEVOUCHE, E. (2012) Restoring psychic containers of identity after a suicide attempt in adolescence, The Bulletin of the Menninger Clinic (no prelo).

FISHER, S. \& CLEVELAND, S. E. (1958) Body Images and Personality. Princeton: New York, Van Nostrand.

FREUD, S. (1912/2001) Totem et tabou. Paris: Petite Bibliothèque Payot. (1915/1968) “Pulsions et destins des pulsions", in Métapsychologie.

Paris: Gallimard, folio essais, p.11-43.

(1981) Essais de Psychanalyse. Paris: Petite Bibliothèque Payot.

(1920) “Au-delà du principe de plaisir”, p.41-115.

(1923) "Le moi et le ça”, p.219-275.

GAMMIL, J. (2006) Quelques réflexions sur l'entrée dans l’adolescence. Adolescence, 58, p.931-942.

GREEN, A. (1979) L’angoisse et le narcissisme. Revue Française de Psychanalyse, $43(1)$, p.45-87.

GUTTON, P. (1991/2003) Le pubertaire. Paris: PUF.

LAPLANCHE, J. (1999) Entre séduction et inspiration: l'homme. Paris: PUF.

MARTY, F. (2003) "L’adolescence comme expérience de la limite", in SCELLES, R. et al. Limites, liens et transformations. Paris: Dunod, p.61-80. et al. Transformer la violence? Traumatisme et symbolisation. Paris: In Press. 
MARTY, F. \& CHAGNON, J.-Y. (2006) Identité et identification à l’adolescence, Encyclopédie Médico-Chirurgicale, Psychiatrie/Pédopsychiatrie, 37-213-A-30. Paris: Elsevier SAS.

MARTY, F. \& DE KERNIER. (2010) La adolescencia como paradigma de límites. Actualidad Psicológica XXXIV (392), Buenos Aires (Argentina), p.12-15.

MILNER, M. (1977) Rôle de l'illusion dans la formation du symbole. Revue Française de Psychanalyse, 5-6, p.844-874.

MORO, M-R. (2004) "L'art du passage à l'adolescence”, in BRACONNIER, A., CHILAND, C. \& CHOQUET, M. Idées de vie, idées de mort. La dépression en question chez l'adolescent. Paris: Masson, p.139-148.

OLINDO-WEBER, S. (2001) Suicides au singulier. Du suicidaire au suicidant: la mort dans l'acte. Paris: L'Harmattan.

POMMEREAU, X. (2001) L’adolescent suicidaire. Paris: Dunod.

ROUSSILLON, R. (1991/2005) Paradoxes et situations limites de la psychanalyse. Paris, PUF. (1999/2008) Agonie, clivage et symbolisation. Paris: PUF.

WINNICOTT, D.W. (1952a/1969) "Psychose et soins maternels", in . De la pédiatrie à la psychanalyse. Paris: Payot, p.187-197. (1952b/1969) “L'angoisse associée à l'insécurité”, in

De la pédiatrie à la psychanalyse. Paris: Payot, p.198-202.

Nathalie de Kernier

nathkernier@wanadoo.fr

Dominique Cupa

cupado@noos.fr 